\title{
EDITORIAL
}

\section{Playful learning}

\author{
A. Mark Langan ${ }^{\mathrm{a}}$ and Fiona Smart ${ }^{\mathrm{b}}$ \\ ${ }^{a}$ School of Science and Environment, Manchester Metropolitan University, Manchester, \\ United Kingdom; ${ }^{b}$ Department of Learning and Teaching Enhancement, Edinburgh Napier \\ University, Edinburgh, United Kingdom
}

\section{Introduction}

Welcome to this themed collection for Research in Learning Technology. These articles collate ideas and practices developed from workshops held at the second Playful Learning Conference in July 2017 (http://conference.playthinklearn.net). It is fair to say that this is an extraordinary conference, designed to explore the intersection between learning and play for adults. The approach and content of the event are intentionally playful, yet underpinned by robust research and exploratory practices. The workshops, keynote speakers, stands and activities are intended to disrupt the temptation for participants to default to mainstream educational thinking. They also provide a space for academics from diverse backgrounds to play, learn and think together. Moseley (2017) curated examples from the inaugural 2016 conference for a previous special issue.

The intention of this collection of articles is to provide an overview of current thinking about play and playfulness in tertiary education, share practices that generate enjoyment within scholarly arenas and challenge what technology is in a 'digital age'. We appreciate that some of the articles stray from the path of what some may consider to be 'learning technology', but we suggest that by taking a wider and inclusive view of 'technology', readers will benefit from a small foray into these 'desire paths' (Nichols 2014). Our focus is learning and play in adulthood and distinct from the large body of literature about play in children that incorporates the ideas of notable developmental psychologists such as Piaget, Vygotsky and Bruner (for an overview, see Lillemyr 2009). Play and playfulness have long been considered fundamental to learning beyond childhood (e.g. Huizinga 1955), across subject areas (e.g. James and Brookfield 2014), and have been proposed as central to creative enquiry and research (e.g. Bateson and Martin 2013). This particular volume of work promotes diverse and creative aspects of playful behaviour and activity design as a means of enhancing adult educational experiences and outcomes.

The types and characteristics of play, and the methods used to encourage playful learning are wonderfully diverse. Playful approaches can provide spaces for learners to be curious, actively participate, enjoy learning activities and be driven by intrinsic motivation, rather than extrinsic, instrumental gains (Whitton 2014). One of the appeals of play in education is an emphasis on exploration and experimentation in

*Corresponding author. Email: M.Langan@mmu.ac.uk 
'safe' environments. This is underpinned by the creation of places where failure is not only accepted, but valued and recognised as valuable for learning. The Higher Education landscape in the United Kingdom is in a dynamic phase and subject to debate regarding the adoption of neoliberal policies in the competitive higher education sector (e.g. Naidoo and Williams 2014). There has long been concern that philosophical realignment of the sector is driving learners to attain instrumental goals, rather than supporting longer-term intellectual development (e.g. Schwartzman 1995). With the accompanying rhetoric that students may be customers or consumers to be pleased, rather than learners with responsibility for their own learning (e.g. Budd 2016; Tight 2013), enjoyable approaches to learning that fire passions of adult learners seem increasingly valuable.

There is little doubt that the sector is responding to publicly available metrics, such as student ratings of their university experiences and measures of student 'success', that form components of public rankings and league tables. We suggest that there is significant potential for more playful educational approaches to improve higher education, for example, by modifying our students' engagement with their courses, learning gain, enjoyment, intrinsic motivation, resilience and attitudes to failure. However, we acknowledge a prevalent counterargument to the value of fun in adult learning arenas, with claims of increasing 'edutainment' or 'technotainment' and fun perceived as 'excessive and to the detriment of learning'. Such contrary discourses highlight the complex relationship between enjoyment and learning gains in a higher education.

The benefits of Playful Learning could be realised much more widely than university courses, for example, corporate training and an array of informal schema for learners of all ages. Commercial organisations have been drawing on more playful activities for many years, to drive training and serve other purposes (Batko 2016; Michael and Chen 2005). Such approaches may reflect how organisations and society may be moving away from bureaucratic or hierarchical foundations towards flexibility in the processes that lead to decision-making and a drive to disrupt mainstream institutional processes (Kane 2004).Perhaps, it is the more constrained, 'traditional' approaches in business and educational sectors that need challenging most, and maybe these are the places that the innovative landscape of play could have the greatest impact. All said, it seems timely to explore and experiment with adult playfulness. Hopefully, the following articles add a few more pieces to a growing puzzle that is, perhaps, being surreptitiously built into the higher education landscape.

\section{Articles in the themed collection}

Nicola Whitton begins the collection with a general overview of the subject area. In suitably playful fashion, Nicola wrote the first draft of this article 'live', developing her narrative openly online. The outcome is a highly valuable overview of core themes, linked to the metaphor of the 'magic circle', and drawing on literature about the nature of playful spaces and participant behaviours and motivations. The article provides a pedagogic rationale for playful learning in higher education and an overview of associated pedagogic tools. Her case studies provide contrasting examples - the Playful Learning Conference format and experimental work developing breakout rooms with students at a secondary school. She concludes with a timely nod to gaps in knowledge and also the challenges to those using adult playful learning approaches. 
Simon Grey and colleagues deliver the first of the collection's articles based on a conference workshop. The article explores the nature of extrinsic and intrinsic motivators for undergraduate software development work, providing a strong case for constructs in higher education based on theories of self-determination and cognitive evaluation/organismic integration. Through experience of 'game jams' and an experimental undergraduate module entitled 'Do whatever you want*', the authors report that using constraints, rather than affording 'free reign', enhanced creativity and intrinsic motivation. They go on to describe how extrinsic motivators reduce creativity and academic risk-taking behaviour.

Simon Warwick and colleagues emphasise the need for greater space for innovation and ideas in a higher education system that is time pressured. The authors describe a playful staff development session based on the British game show 'The Crystal Maze' as an enjoyable example of gamification. The 'Crys-TEL' maze challenges staff teams to solve learning and teaching problems collaboratively. The approach is informed by commercial gamification innovations, particularly surrounding use of rewards and leaderboards. The authors acknowledge that simply gamifying activities does not automatically make them engaging and go on to describe how they developed their approach through a '6D' approach to gamification. The descriptions of the approach, constraints and outcomes are useful, honest and illuminating, particularly their experiences with some issues surrounding the accessibility of their activities.

Rosie Jones led one of the overarching conference activities where many participants opted to take part in a social media game using a Twitter soft toy alter ego. Delegates without a toy on arrival were given the chance to adopt one and those who took part saw their characters involved with toy 'missions', a toy puzzle for delegates to solve and a 'toy keynote'. The article notes how social media tools are changing industries, including academia, but its role is often limited to event 'backchannels'. The ideas described and evaluated provide an excellent example of how social media can develop and support communities of practice. It is acknowledged that parts of the game were overly ambitious and also that some delegates were uncomfortable with the game prior to the conference (but by the end of the conference were very positive). Others expressed enjoyment at the freedom the toy avatar gave them and the potential for rebellious activity that this afforded. The article concludes with some guidance for running similar games and example tweets and photos.

Sam Illingworth and colleagues complete the themed collection with their proposal that tabletop games are technology and that their use can contribute to the wider discussion about the benefits of play. A brief history of analogue games is provided, supported by a framework of what play is in the context of playing games, drawing particularly on the work of Bernie De Koven. The example is based on a card game 'Gloom', where players attempt to assemble the most unhappy family. The game mechanics are embellished by a storytelling component, and the notion of enjoyment surrounding points scoring and storytelling success are discussed. Using explorations of the participants' own favourite games, the balance of structure and story are explored. The authors found a great deal of variability in what was considered to be play. The ensuing debate about the terms 'play' and 'fun' is couched in a useful theoretical framework. Ultimately, analogue games are suggested to have the potential to outperform their digital counterparts in terms of the enhancement of sociable behaviours, accessibility and ease at which they can be adapted to suit player's needs. 


\section{A.M. Langan and F. Smart}

\section{Opportunities}

Playfulness is a valuable trait, apparent in animal evolution and strongly linked to human creativity, learning and sociality. Often, it just needs an opportunity to emerge. This collection describes some vehicles to elicit playfulness and ways to help adults to have the freedom to benefit from play and playfulness. The eminent animal biologist Patrick Bateson (2015) provides a persuasive case for encouraging playful play, he suggests:

The motivation to be playful comes from within. No external bribes are needed. In fact attempting to encourage such activity with food or money is likely to be counterproductive. Having fun is a good reason to be playful. The pleasure it generates could be seen as its primary benefit.

Perhaps, the well-being that playfulness supports is reason enough to encourage playfulness during learning, but the associated creativity and productivity are reasons to harness and weave it into the serious side of modern life. Good design and management by the creators are probably needed to open the door, and good humour of the participant may be needed to help them to stay and play. The only failures would be to not allow those that wanted to join in, to have the chance to be invited and decide for themselves and for those with good ideas to encourage play to not try out their ideas and share them. We thank all of our contributors for describing their views and explorations of playful learning and hope these ideas continue to evolve, bring enjoyment and drive learning.

\section{References}

Bateson, P. (2015) 'Playfulness and creativity', Current Biology, vol. 25, no. 1, pp. R12-R16.

Bateson, P. \& Martin, P. (2013) Play, Playfulness, Creativity and Innovation, Cambridge University Press, Cambridge, UK.

Batko, M. (2016) 'Business management simulations - a detailed industry analysis as well as recommendations for the future', International Journal of Serious Games, vol. 3, no. 2, pp. 47-65.

Budd, R. (2017) 'Undergraduate orientations towards higher education in Germany and England: problematizing the notion of "student as customer", Higher Education, vol. 73, no. 1, pp. 23-37.

Huizinga, J. (1955) Homo Ludens: A Study of the Play Element in Culture, Beacon Press, Boston, MA.

James, A. \& Brookfield, S. (2014) Engaging Imagination: Helping Students Become Creative and Reflective Thinkers, Jossey Bass, San Francisco, CA.

Kane, P. (2004) The Play Ethic: A Manifesto for a Different Way of Living, Macmillan, London, UK.

Lillemyr, O. F. (2009) Taking Play Seriously: Children and Play in Early Childhood EducationAn Exciting Challenge, Information Age Publishing, Charlotte, NC.

Michael, D. \& Chen, S. (2005) Serious Games: Games that Educate, Train, and Inform, Thomson Course Technology, Boston, MA.

Moseley, A. (2017) 'Editorial: playful learning', International Journal of Game-Based Learning, vol. 7, no. 3, [online] Available at: https://www.igi-global.com/pdf. aspx?tid $\% 3 \mathrm{D} 182557 \% 26 \mathrm{ptid} \% 3 \mathrm{D} 158644 \% 26 \mathrm{ctid} \% 3 \mathrm{D} 15 \% 26 \mathrm{t} \% 3 \mathrm{DPlayful} \% 20$ Learning

Naidoo, R. \& Williams, J. (2014) 'The neoliberal regime in English higher education: charters, consumers and the erosion of the public good', Critical Studies in Education, vol. 2, pp. 208-223. 
Nichols, L. (2014) 'Social desire paths: a new theoretical concept to increase the usability of social science research in society', Theory and Society, vol. 43, pp. 647-665.

Schwartzman, R. (1995) 'Are students customers? The metaphorical mismatch between management and education', Education, vol. 116, no. 2, pp. 215-222.

Tight, M. (2013) 'Students: customers, clients or pawns?', Higher Education Policy, vol. 26, no. 3, pp. 291-307.

Whitton, N. (2014) Digital Games and Learning: Research and Theory, Routledge, New York. 